\title{
23. ORIGIN OF THE NATURAL REMANENT MAGNETISM OF SHEETED DIKES IN HOLE 504B CORED DURING LEGS 137 AND 140 ${ }^{1}$
}

\author{
S. Allerton, ${ }^{2}$ J.E. Pariso, ${ }^{3}$ L.B. Stokking, ${ }^{4}$ and E. McClelland ${ }^{2}$
}

\begin{abstract}
The natural remanent magnetism of samples from the sheeted dike complex generated at the Costa Rica Rift, drilled in Deep Sea Drilling Project/Ocean Drilling Program Hole 504B, can be resolved into a vertical drilling induced remanent magnetization and a shallow stable remanence by alternating field and thermal demagnetization. We investigate the unblocking temperature and coercivity spectra of these components, and compare these to spectra of thermal, induced, and viscous magnetizations imparted in the laboratory. The drilling-induced remanence is not a simple thermal, induced, or viscous remanence, but probably a piezoremanence acquired in an elevated field. The stable remanence may be a thermal remanence. Comparison of the stable remanence in altered and fresh samples indicates that natural remanent intensity and bulk susceptibility are reduced in more altered samples, but the stability and direction are similar to those in fresh samples.

Whereas the stable components of the sheeted dike complex as a whole have a mean inclination of $-18^{\circ} \pm 17^{\circ}$, individual lithologic units exhibit much less scatter and significantly different inclinations. A plausible explanation is that the stable remanence is a thermal remanence or a rapidly acquired chemical remanence, which does not average secular variation. The distribution of the inclination data suggests that dikes may be intruded as multiples.
\end{abstract}

\section{INTRODUCTION}

The acquisition of the natural remanent magnetism (NRM) at the ridge axis during the spreading process is a fundamental feature of the Vine Matthews hypothesis (Vine and Matthews, 1963) for the interpretation of marine magnetic anomalies. Initially the magnetization was considered to be a thermal remanent magnetism (TRM), but subsequent work has emphasized the significance of chemical alteration as a process that can alter the magnetic anomaly signature of the NRM over time (Smith and Banerjee, 1986; Kelso et al., 1991). The variation of the process of NRM acquisition with depth, with corresponding changes of grain size and mineralogy, will control the nature of reversal boundaries. In addition, where paleomagnetic data are used to reorient structural features, it is crucial to understand the nature and relative timing of the magnetic components.

Our knowledge of the magnetism of the sheeted dike complex of the oceanic crust is largely based on unoriented dredge samples from deeper crustal exposures of the oceanic lithosphere (e.g., Fox and Opdyke, 1973) and from studies of ophiolites (Vine and Moores, 1972; Banerjee, 1980; Hall et al., 1987), both in anomalous tectonic situations. The only location where the sheeted dike complex has been sampled in situ is at Deep Sea Drilling Project (DSDP)/Ocean Drilling Program (ODP) Hole 504B, drilled in 5.9 Ma crust south of the intermediate spreading rate Costa Rica Rift (e.g., Becker et al., 1989; Dick, Erzinger, Stokking, et al., 1992). Hole 504B penetrates to $2000 \mathrm{mbsf}$ through sediments and extrusive basalts into the sheeted dike complex (SDC), making it the deepest drill hole in the oceanic basement, representing an important reference section for studies of the magnetism of the oceanic crustal sequence.

In this contribution we investigate the directional nature of the components of magnetization determined for samples from the lower part of the SDC cored on ODPLegs 137 and 140. In addition, we have attempted to model the coercivity and unblocking temperature spec-

\footnotetext{
'Erzinger, J., Becker, K., Dick, H.J.B., and Stokking, L.B. (Eds.), 1995. Proc. ODP, Sci. Results, 137/140: College Station, TX (Ocean Drilling Program).

${ }^{2}$ Department of Earth Sciences, University of Oxford, Parks Road, Oxford OX1 3PR, United Kingdom.

${ }^{3}$ School of Oceanography, University of Washington, Seattle, WA 98195 , U.S.A.

${ }^{4}$ Ocean Drilling Program, Texas A\&M University Research Park, 1000 Discovery Drive, College Station, TX 77845-9547, U.S.A.
}

tra of these components by acquiring magnetizations under laboratory conditions. We discuss the implications of these results for the process of dike intrusion.

\section{MAGNETIC MINERALOGY}

Previous work on the SDC from Hole 504B (e.g., Pariso and Johnson, 1989, 1991; Pariso et al., this volume; Shau et al., 1993; Fig. 1) has suggested that the magnetization is dominantly carried by grains with magnetite and ilmenite intergrowths that have formed by deuteric alteration on slow cooling from an original primary titanomagnetite. Hydrothermal alteration has corroded these grains, removing magnetite and altering ilmenite to sphene. The grains are often large ( $>20 \mu \mathrm{m}$ in diameter), although their lamellae structure may give them single domain (SD) properties (e.g., Davis and Evans, 1976). Pervasive hydrothermal alteration significantly reduces the bulk susceptibility and NRM intensity.

We have investigated the temperature dependence of low-field susceptibility (see "Appendix"). The magnetic minerals are dominated by a phase with a Curie point in the $580^{\circ}-600^{\circ} \mathrm{C}$ range, indicating pure magnetite. The unblocking temperature spectra of the multidomain (MD), and the pseudo-single domain (PSD) and SD grains were determined by thermal demagnetization of a saturation induced remanent magnetism (IRM) (at 0.8 T; Fig. 2A; see "Appendix"). Results of this experiment indicate that little SD and PSD material is unblocked below about $300^{\circ} \mathrm{C}$, and most unblocks between $300^{\circ} \mathrm{C}$ and the Curie temperature $\left(580^{\circ} \mathrm{C}\right)$. In contrast, the $\mathrm{MD}$ component unblocks gradually between $0^{\circ} \mathrm{C}$ and $500^{\circ} \mathrm{C}$. Above $500^{\circ} \mathrm{C}$ new mineral growth dominates the magnetization, masking the original components.

The coercivity spectra of the MD and PSD + SD grains were investigated by AF demagnetization of the saturation IRM (Fig. 2B; see "Appendix"). This experiment also indicates that the coercivity spectrum of the MD grains is in the range $0-25 \mathrm{mT}$, similar to that of the drilling-induced remanent magnetization (DIRM), and the spectrum of the SD grains is between 0 and $100 \mathrm{mT}$.

\section{Components of Natural Remanent Magnetism}

Samples have been analyzed using both stepwise alternating field (AF) and thermal demagnetization techniques. As the core is oriented only with respect to a vertical, only the inclination can be related to 


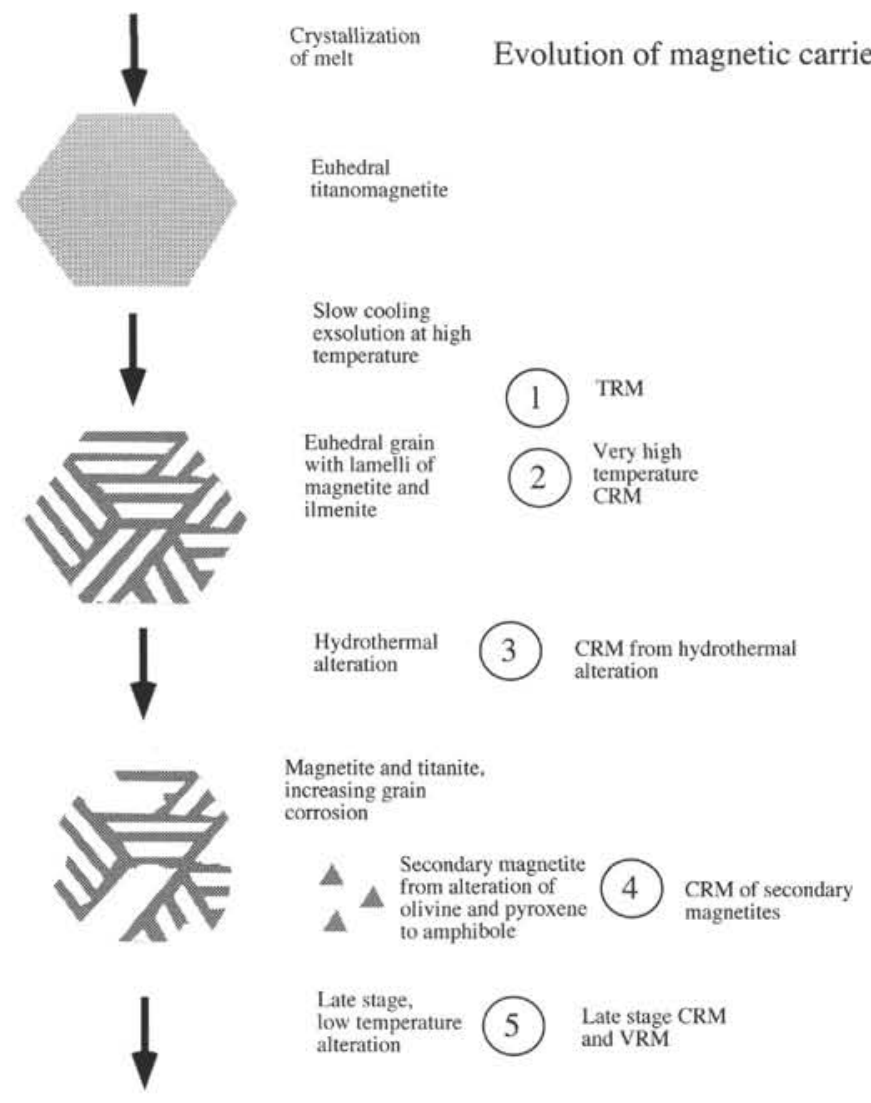

Figure 1. Evolution of magnetic carriers, summarized after Pariso and Johnson (1991). Circled numbers correspond to possible acquisition of magnetization discussed in the text.

an external reference. In the majority of samples, a steep, upward directed component has been isolated between $0^{\circ} \mathrm{C}$ and $400^{\circ} \mathrm{C}$ (Fig. $3 \mathrm{~A}$ ) and between 0 and $25 \mathrm{mT}$ (Fig. 3B). We shall go on to argue that this component represents an overprinting DIRM, as also concluded by Pariso and Johnson (1989). Between $400^{\circ} \mathrm{C}$ and $550^{\circ} \mathrm{C}$ of thermal treatment, and below $100 \mathrm{mT}$ of $\mathrm{AF}$ treatment, a stable remanence, typically with shallow inclinations, can be isolated. In some samples the DIRM swamps this stable remanence, but in most samples the stable remanence is well defined in the high coercivity ( $>25 \mathrm{mT}$ ) range, and can be picked with some precision. We will produce evidence that this stable component is the characteristic remanence, that it was acquired relatively rapidly following dike intrusion, and that it may represent a TRM.

The unblocking temperature spectra of the samples can be separated into two components (Fig. 4A). The low-temperature DIRM component is evenly distributed in the range $0^{\circ}-400^{\circ} \mathrm{C}$, and the high-temperature component unblocks between $350^{\circ}$ and $580^{\circ} \mathrm{C}$. AF demagnetization indicates that the coercivities of the DIRM component are between 0 and $25 \mathrm{mT}$ (Fig. 4B) and the stable component is in the range $0-100 \mathrm{mT}$, with a distinct overlap in the low coercivity range occupied by the DIRM.

\section{INVESTIGATION OF NATURE OF COMPONENTS OF NRM}

We have investigated the nature of the NRM by remagnetizing the samples using different acquisition mechanisms, and comparing the unblocking temperature and coercivity spectra with those of the NRM. This approach cannot conclusively prove the nature of the remanence, but it does allow us to identify which acquisition processes may contribute, and to discount those that do not. We also have made extensive
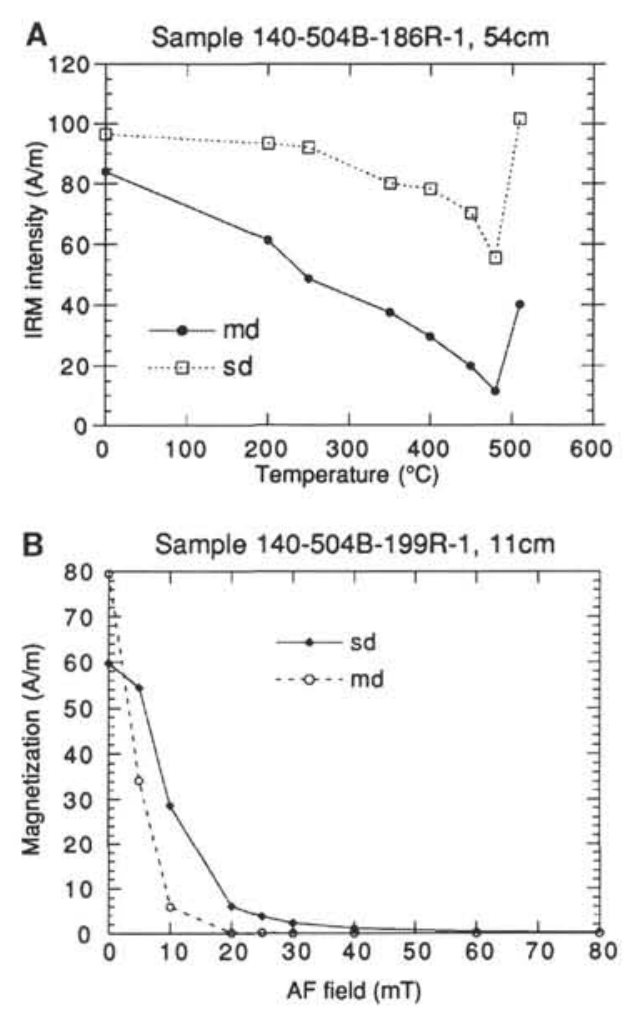

Figure 2. A. Thermal demagnetization of saturation IRM (see "Appendix" for discussion of experimental method). Sample 140-504B-186R-1, $54 \mathrm{~cm}$. B. AF demagnetization of saturation IRM (see "Appendix" for discussion of experimental method). Sample 140-504B-199R-1, $11 \mathrm{~cm}$.

use of low temperature demagnetization (see "Appendix") to separate MD contribution to remanence from that of SD and PSD.

We have attempted to model the drilling-induced remanence as an IRM, as a viscous remanent magnetism (VRM), and as a partial thermal remanent magnetism (PTRM), and the stable remanence as a TRM.

\section{Drilling-induced Remanent Magnetization (DIRM)}

Vertical, magnetically soft DIRMs are commonly associated with cores from deep boreholes (e.g., Ade-Hall and Johnson, 1976; Lowrie and Kent, 1976; Audunsson and Levi, 1989; Kodama, 1984; McWilliams and Pinto, 1988). The process that produces the DIRMs appears to affect many rock types; both igneous and sedimentary, and so is unlikely to be a chemical effect. Some authors (Audunsson and Levi, 1989, McWilliams and Pinto, 1988) have suggested an IRM origin for this component, resulting from magnetic contamination from the drill string, although they also recognize that piezoremanent magnetism (PRM) and shock effects may also contribute (e.g., Kodama, 1984). AF demagnetization of cores from Leg 148, again to Hole 504B (Alt, Kinoshita, Stokking, et al., 1993) has not identified any consistent drilling-induced component. This surprising observation may result from the use of new drill collars on the early part of this leg. These collars had not been inspected using the "Magnafluxing" technique, in which large magnetic fields are applied to the pipe in an attempt to identify microfractures. They therefore lack the strong magnetism that otherwise appears to contaminate the cores.

Comparison of the results of the unblocking temperatures of saturation IRM and the NRM suggests that the DIRM is dominantly carried by MD grains. AF demagnetization of the saturation IRM also indicates that the coercivity spectrum of the MD grains is in the range 0-25 mT, similar to that of the DIRM, and the spectrum of the SD 
A

Sample 214R-1, 49cm
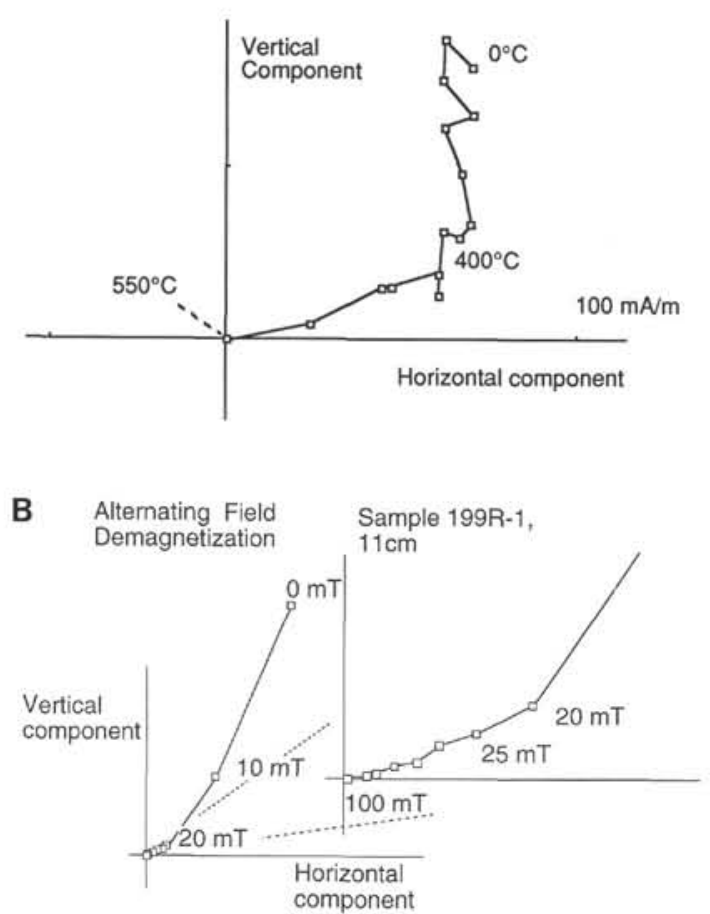

Figure 3. A. Thermal demagnetization of NRM; orthogonal plot (projected into vertical plane containing the stable component). Sample 140-504B-214R-1, $49 \mathrm{~cm}$. B. AF demagnetization of NRM; orthogonal plot (projected into vertical plane containing the stable component). Sample 140-504B-199R-1, $11 \mathrm{~cm}$.

grains is between 0 and $100 \mathrm{mT}$, corresponding closely to that of the stable component of the NRM.

We have attempted to model the DIRM as a simple IRM induced in a field of $1 \mathrm{mT}$, sufficient to produce a similar intensity as the initial NRM. AF demagnetization at $5 \mathrm{mT}$ completely removes this IRM, and no higher coercivity grains are affected, in contrast to the DIRM, which has affected grains in the $5 \mathrm{mT}-25 \mathrm{mT}$ coercivity range. The field that would affect coercivities up to $25 \mathrm{mT}$ would produce a magnetization many times greater than the NRM. The magnetic hardness of the DIRM compared with the IRM leads us to conclude that the DIRM is not a simple IRM.

The origin of the DIRM as a TRM has been considered by applying a modified Thellier-Thellier experiment (Thellier and Thellier, 1959; Coe, 1967; see "Appendix"). The results of this experiment (Fig. 5) show a poorly linear gradient in the temperature range of the unblocking temperature spectrum of the DIRM, with a slope of $\sim 7$ (implying a field of $240 \mu \mathrm{T}$ ). Linearity of this part of the curve may not be expected because the MD component would not be expected to obey the law of additivity of PTRM required for the ThellierThellier technique. The unblocking temperature spectrum of this component is up to $400^{\circ} \mathrm{C}$, well above the maximum temperature at the base of the hole, and it is unlikely that a simple TRM process can be the origin of this magnetization.

We next consider the possibility that the DIRM is a VRM acquired in the elevated temperature conditions encountered at the base of the hole, and in a field several times that of the Earth. The base of the hole is hot, with temperatures initially at about $200^{\circ} \mathrm{C}$, and cooling to about $150^{\circ} \mathrm{C}$ during drilling. The interval between cores is typically about 8 $\mathrm{hr}$. We have modelled the VRM acquisition process at elevated temperatures by heating a sample at $150^{\circ} \mathrm{C}$ for $6 \mathrm{hr}$ in an axial field of 250 $\mu \mathrm{T}$ (the maximum field attainable in the oven). The resultant coercivity spectrum is shown in Figure 6. A small fraction in the coercivity range $5 \mathrm{mT}-20 \mathrm{mT}$ has been remagnetized by this process, although not the
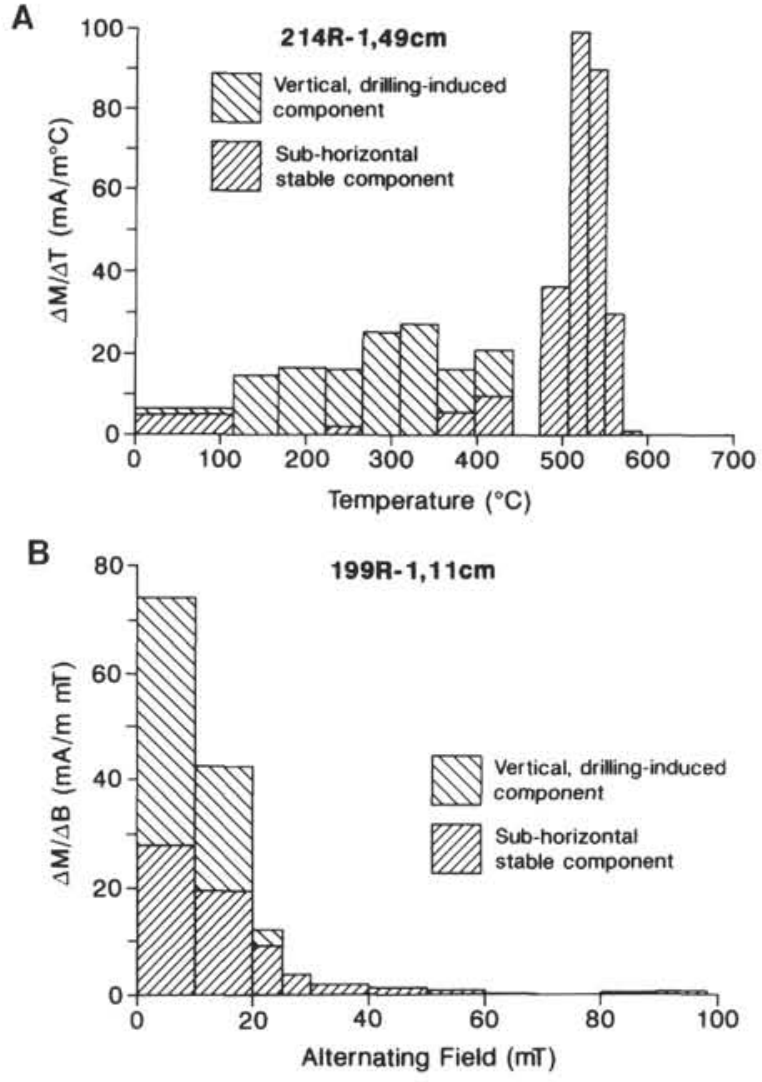

Figure 4. A. Unblocking temperature spectrum: Sample 140-504B-214R-1, 49 $\mathrm{cm}$. B. Coercivity spectrum: Sample 140-504B-199R-1, $11 \mathrm{~cm}$.

same proportion as is seen in the DIRM, suggesting that the DIRM is not simply a VRM. The sample used for this experiment was previously cleaned using tumbling $\mathrm{AF}$ treatment, which puts the domain walls of the MD grains in a stable state and alters their relative magnetic hardness. It is difficult to assess whether this effect has totally compromised this experiment, or merely slightly modifies the result.

Although they identify an IRM as the main source of DIRM, Audunsson and Levi (1989) suggest that piezoremanence also may contribute. Kodama (1984) also concludes that PRM is the main contributor to the DIRM. Pressure acts on multidomain grains by reducing the amplitude of the domain walls (O'Reilly, 1984) to the point where they cease to act as energy barriers, and the magnetization of the grain follows the external field. Kern (1961) demonstrates a relationship between coercive force and stress:

$$
S_{m}=3.8 \times 10^{9} H_{m}
$$

where $S_{m}$ is the minimum coercive stress $(\mathrm{Pa})$, and $H_{m}$ is the coercive force (T). Rocks recovered on Legs 137 and 140, initially at a lithostatic stress of about $100 \mathrm{MPa}$, will have undergone a reduction of the pressure as they are drilled and brought to the surface. This will produce a resultant increase in the size of the domain walls trapping the field associated with the drill string in grains with coercive forces less than about $25 \mathrm{mT}$, which is similar to the coercivity range of MD material carrying the DIRM component.

As a result of these experiments and arguments, we suggest that the DIRM is probably strongly influenced by piezoremanence, with some contribution from VRM acquired in an elevated temperature. The high fields in the drill collar are likely to control the magnitude of the magnetization acquired by these processes, but not the relative hardness of the DIRM. 
A
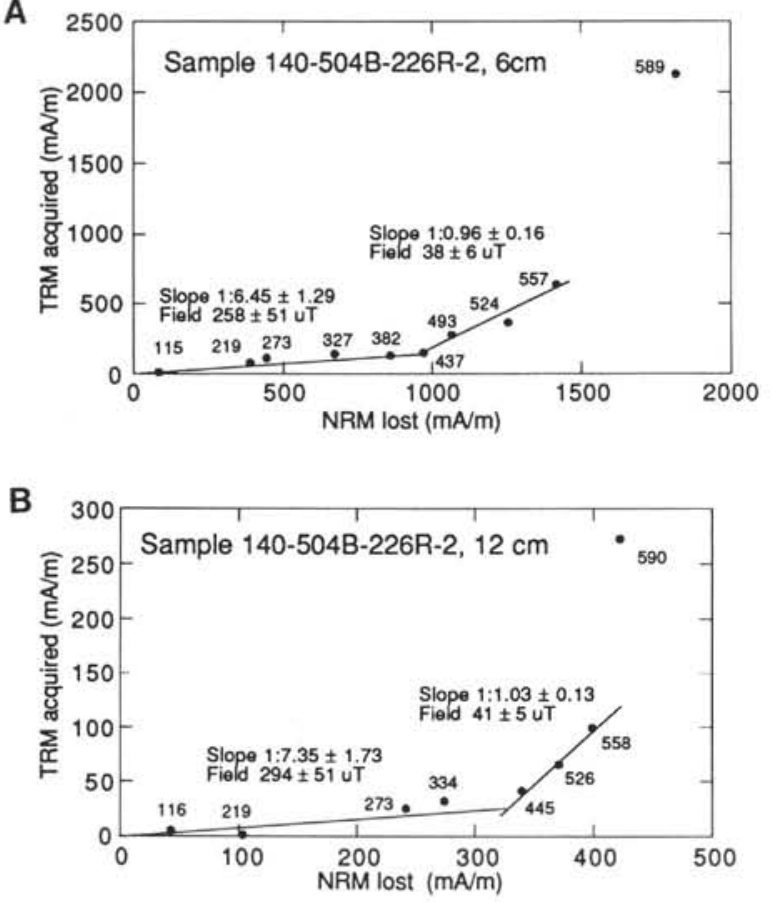

Figure 5. Results of modified Thellier-Thellier experiment. A. Sample 140504B-226R-2, $6 \mathrm{~cm}$. B. Sample 140-504B-226R-2, $12 \mathrm{~cm}$.

\section{Stable Remanence}

The unblocking temperature of the stable remanence is in the range $350^{\circ}-580^{\circ} \mathrm{C}$, similar to the SD range, although with some overlap with the MD unblocking temperature spectra, so it is likely that this component is dominantly carried by SD grains, with some subsidiary MD grains. The saturation magnetization (at $0.8 \mathrm{~T}$ ) after different temperature steps increases slightly in the $500^{\circ}-600^{\circ} \mathrm{C}$ range, indicating some growth of new SD magnetic minerals ( $25 \%$ increase).

The Thellier-Thellier experiments generally indicate that in the range $400^{\circ}-560^{\circ} \mathrm{C}$, a gradient of $\sim 1: 1$ (in a $40 \mu \mathrm{T}$ field) was obtained, although in most cases not enough points were recorded in this temperature interval to define the gradient precisely. Above this temperature, the TRM increased dramatically and nonlinearly, probably reflecting the growth of new SD phases. In two cases, Samples 140504B-226R-2, $6 \mathrm{~cm}$, and 140-504B-226R-2, $12 \mathrm{~cm}$ (Fig. 5), gradients could be calculated on four and three points, respectively. Assuming a proportional relationship between the NRM, TRM, and the natural and laboratory fields, this indicates that the stable component is comparable to TRM growth in fields of $38 \pm 6 \mu \mathrm{T}$ and $41 \pm 5 \mu \mathrm{T}$, respectively; of the same order as the present field $(33 \mu \mathrm{T})$. These results are all consistent with the hypothesis that the stable remanence is a TRM acquired during cooling. A chemical remanent origin, producing a grain-size range that mimics a TRM, cannot, however, be precluded.

The two samples discussed above are paired samples from a single piece of core. Sample 140-504B-226R-2, $6 \mathrm{~cm}$, is from a relatively fresh rock, and Sample 140-504B-226R-2, $12 \mathrm{~cm}$, is from an adjacent pervasively altered patch. The intensity of NRM and the bulk susceptibility are significantly lower in the altered sample than in the fresh sample, indicating a reduction in the amount of magnetite in this altered sample. The response to the Thellier experiments is similar. In these as in other paired samples, the directional components are also similar, as are the coercivity spectra. This suggests that the pervasive alteration does not change the mineralogy or reset the magnetization of the grains, but rather reduces the number of grains that carry a magnetization.

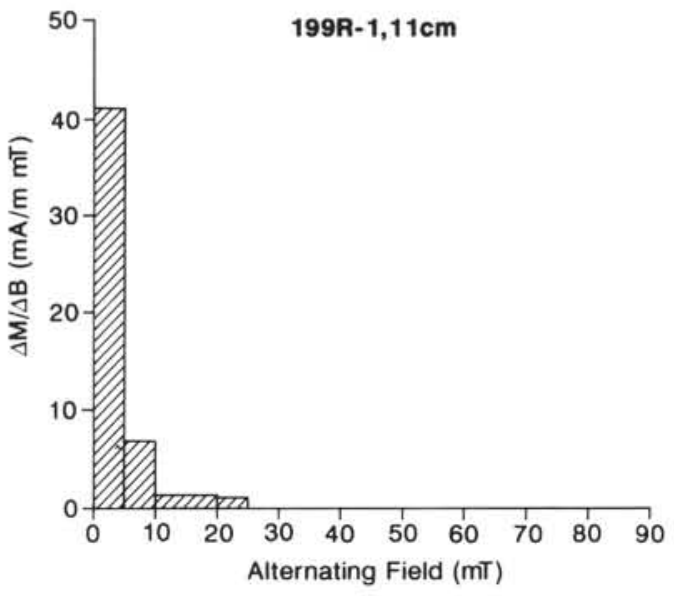

Figure 6. Coercivity spectrum of VRM acquired in axial field of $250 \mu \mathrm{T}$ at $150^{\circ} \mathrm{C}$ for $6 \mathrm{hr}$. Sample 140-504B-199R-1, $11 \mathrm{~cm}$.

Optical studies indicate a multiphase origin for the magnetic grains (Pariso and Johnson, 1991, Pariso et al., this volume). Initial euhedral titanomagnetites grew and then underwent deuteric alteration in the early stages of cooling. The activity of hydrothermal fluids corrodes the grains, removing both $\mathrm{Fe}$ and $\mathrm{Ti}$. We suggest that this alteration completely or partially destroys the grains, but without causing recrystallization and remagnetization of the remaining magnetites.

\section{Directions of Stable Magnetization}

The direction of the stable remanence can give additional information on the nature of the remanence. As the cores are free to rotate within the core barrel, the declination is not constrained, and only the inclination can be used for directional analysis.

The deviations of the borehole from vertical are of significance to measurements of the relative inclinations of features observed in the core. Borehole deviation was measured using the caliper log and the inclinometry section of the Formation MicroScanner (FMS) run on Leg 148 to Hole 504B (Alt, Kinoshita, Stokking, et. al, 1993). In the section of interest between 1500 and 2000 mbsf, the deviation of the borehole from the vertical gradually increases from about $2^{\circ}$ to $5^{\circ}$ to the northeast, and is therefore not a major contributor to the variation in the inclinations.

The precision of the stable inclination data is generally high; we have here only included data with a clear linear stable component, defined by a minimum of three data points, and directed toward the origin. The inclination is variable, with a mean value of $-18^{\circ}$ and a standard deviation of $17^{\circ}$.

When the inclinations are plotted against depth downhole, the data cluster into distinct groups (Fig. 7A). This is more evident on a plot of stable magnetic inclination vs. lithologic unit (Fig. 7B). On this plot it is clear that scatter of data from individual units is often very small, whereas the scatter between units is often much larger.

The results from two of the largest units, Unit 227 and Unit 260, can be compared (Fig. 8), assuming a Fisherian distribution and calculating an $\alpha_{95}$ cone of confidence from McFadden and Reid (1982). Assuming that the declinations are similar, the two directions can be shown to be from two statistically significantly distinct populations (using McFadden and Lowes, 1981). This result suggests that the observed variation is real, rather than due simply to errors in measurement. Furthermore, this result suggests that the stable magnetization has not been affected by a long-term time-averaging process, such as would be produced during low-temperature alteration and which may be expected to generate a similar variation in a single unit as is observed in the entire sequence. The spread of inclinations $\left(17^{\circ}\right)$ is comparable to that predicted from models of secular variation at this latitude (McFadden and Merrill, 1975). 
A

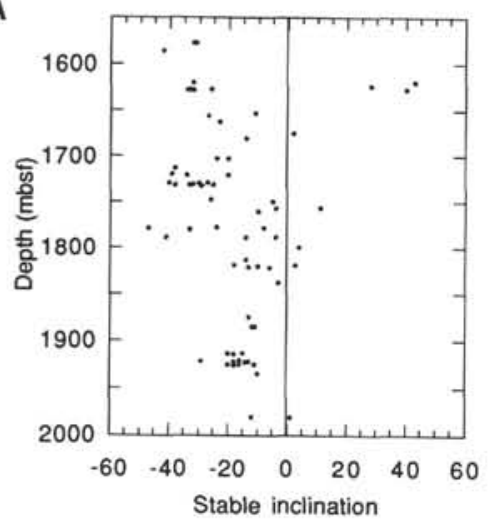

B

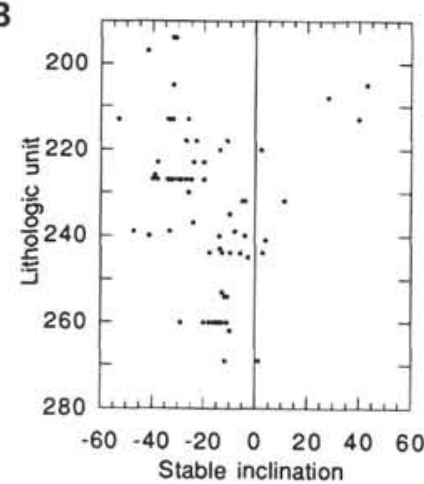

Figure 7. A. Stable magnetic inclination plotted vs. depth (mbsf). B. Stable magnetic inclination plotted vs. lithologic unit.

As well as consistency within individual units, groups of adjacent units show similar inclinations. Groups can be identified between the top of the core recovered on Leg 137 (Unit 194) and Unit 227, between Unit 228 and Unit 246, and between Unit 252 and Unit 269. The origin of this grouping will be discussed further in the "Discussion" section.

\section{Acquisition of Stable Remanence}

The following conclusions can be drawn from the experimental work discussed above, with regard to the nature of the stable remanence:

The NRM has an unblocking temperature spectrum similar to that of a laboratory-grown TRM in the temperature interval of the stable remanence. Pervasive alteration has reduced the intensity of NRM and bulk susceptibility without any other apparent change to the directions or to the coercivity spectrum of the NRM (Pariso and Johnson, 1991).

Samples from individual lithologic units give similar directions; different units yield different directions. The spread of inclinations is comparable to that of secular variation.

The history of the magnetic grains has been detailed by Pariso and Johnson (1991). Their results are summarized in the section on magnetic mineralogy and in Figure 1. We can identify several stages within this history during which magnetizations may be acquired:

1. If the exsolution from titanomagnetite to magnetite and ilmenite occurs above the Curie point, then the samples will acquire a TRM as the grains cool below the Curie temperature. Acquisition of the NRM at this stage would fulfill all the criteria discussed above. It would also require the magnetization to be unchanged by subsequent alteration processes.

2. If exsolution continues at temperatures less than the Curie temperature, then the grain may acquire a very high-temperature

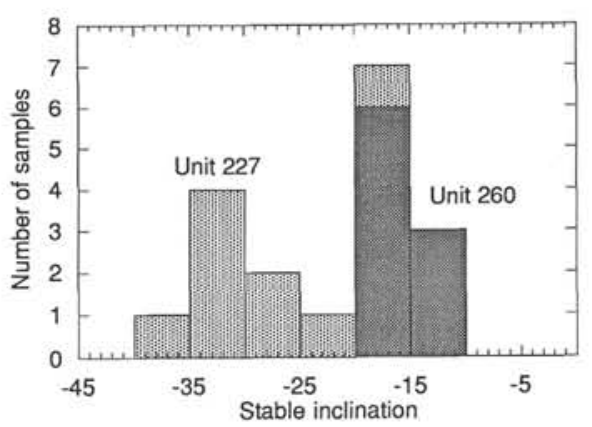

Figure 8. Histogram of stable magnetic inclinations for Unit 227 and Unit 260.

chemical remanent magnetism (CRM). If this CRM could mimic a TRM, then this process could account for the NRM.

3. Hydrothermal alteration may produce a degree of recrystallization and internal grain/domain wall reorganization, during which a CRM may be acquired. We can discount this mechanism as the dominant process: It would require hydrothermal alteration to be relatively rapid and restricted to individual, or small groups of, dikes; and it would require the CRM to mimic a TRM. In addition, the process would have to remagnetize both weakly (5\%) and strongly (40\%) altered samples to the same extent.

4. Small secondary magnetites grow and acquire a CRM during hydrothermal alteration of olivine and pyroxene. Pariso and Johnson (1991) note that these grains are not volumetrically significant, but, because of their small grain size, may be an important contributor to the SD fraction. The small grains almost certainly carry a CRM, but we can discount them as the main carriers of the stable remanence because one would expect to see greater intensities of NRM where alteration was most intense. One sees the opposite.

5. Late-stage, low-temperature alteration may produce some internal reorganization of grains, leading to CRM acquisition. A long period of exposure to the Earth's field will produce a VRM in grains with a short relaxation time $(<6 \mathrm{Ma})$, although these grains are likely to be overprinted by the DIRM and may not affect the high stability $\mathrm{SD}$ grains carrying the stable remanence.

Following this reasoning, we conclude that the most plausible source of the NRM is either a TRM or a very high-temperature CRM acquired rapidly after dike intrusion.

\section{DISCUSSION}

\section{Recommendations for Removal of DIRM}

The removal of DIRM can be a significant problem for ODP drilling in hard rocks, particularly as the coercivity spectra of the DIRM and stable remanence overlap. Thermal treatment is not always a suitable alternative, as this process can ruin samples for further shipboard study. If the DIRM is carried dominantly by the MD magnetite fraction, then an alternative may involve low-temperature/ low-field treatment. This can be done easily by cooling samples in liquid nitrogen, in a thermos within a $\mu$-metal box, and then transferring rapidly to a second $\mu$-metal box containing water.

\section{Implications of Rapid Acquisition of Stable Remanence}

We have argued above that the stable remanence was acquired rapidly, on a time scale that is short compared to secular variation, and that it may be a TRM. If this is true, the variation of the stable magnetic inclinations with depth and lithologic unit (Fig. 7B) can provide important information on the nature of dike intrusion.

Structural evidence suggests that the dike sequence is tilted between $5^{\circ}$ and $10^{\circ}$ (Dick, Erzinger, Stokking, et al., 1992; Allerton et al., this volume), so that between 50 and 1001 -m-thick dikes would 
A
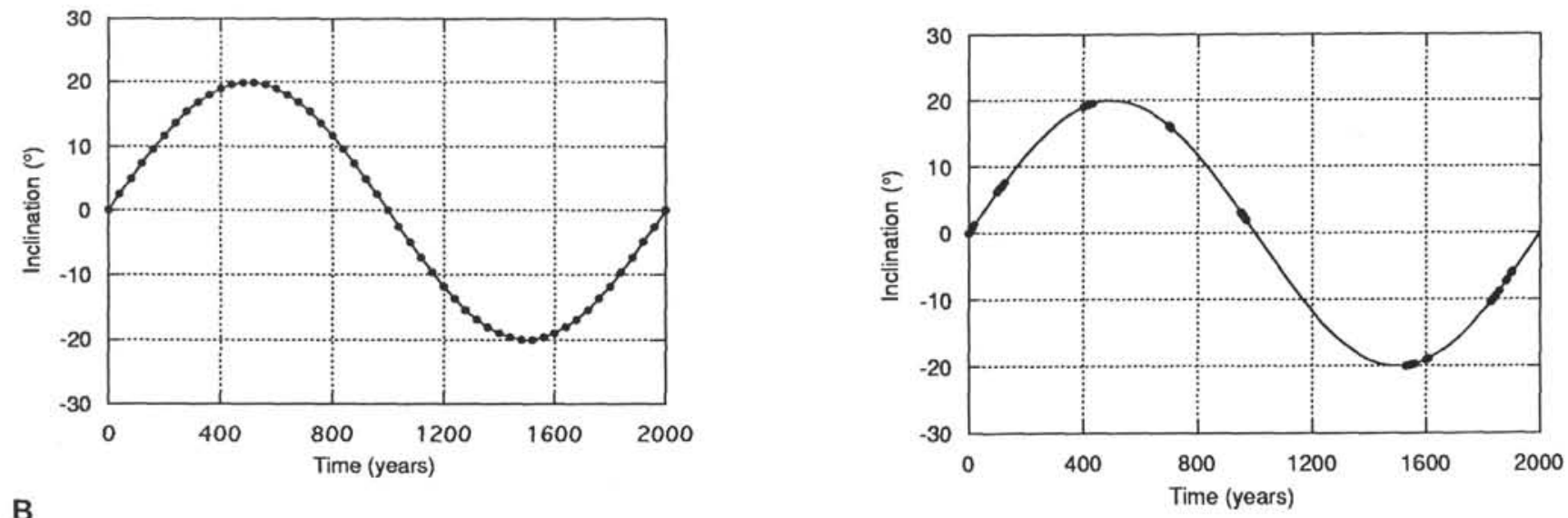

B
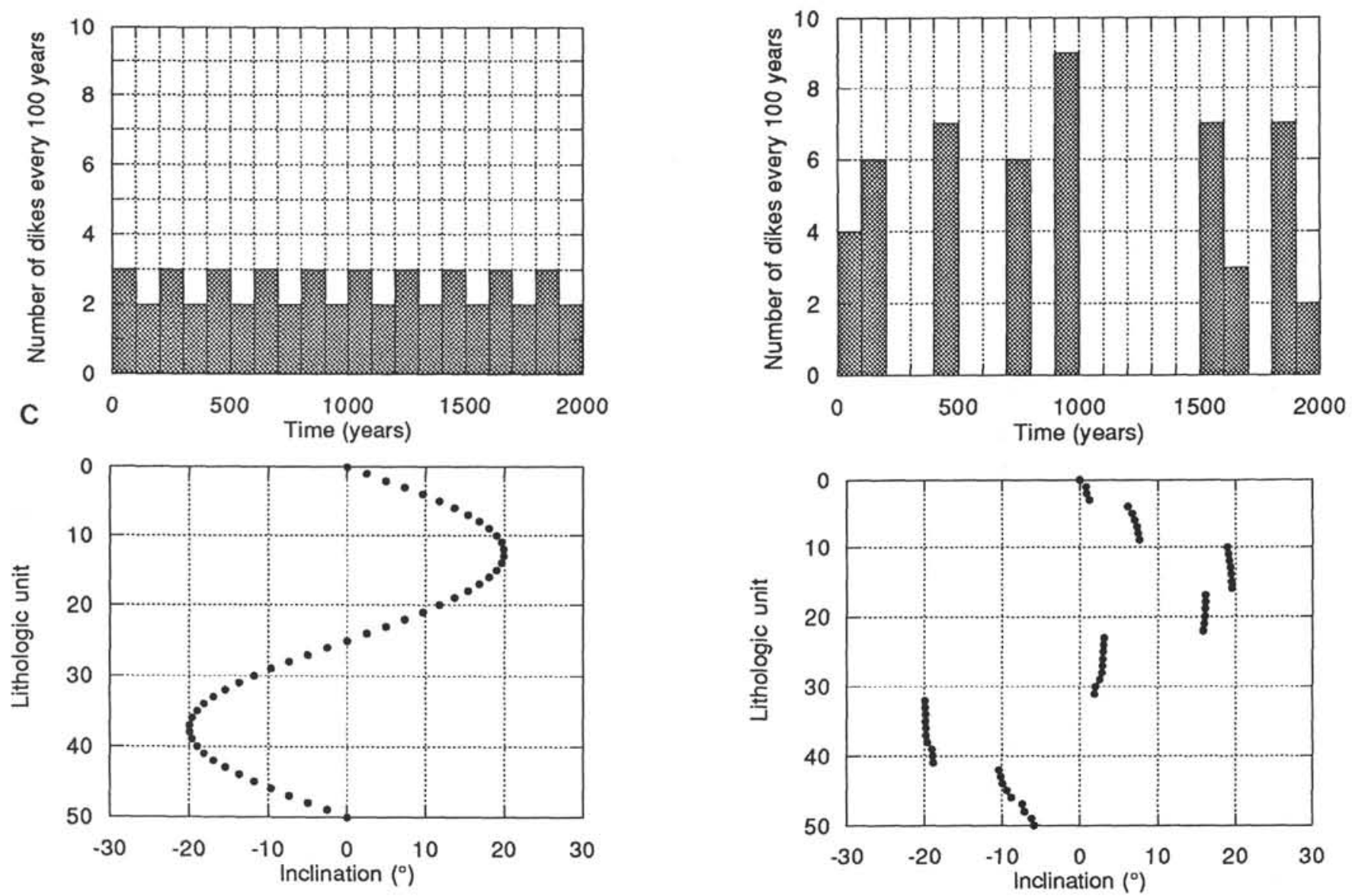

Figure 9. Secular variation illustrating the effect of 50 dikes intruding into a secularly varying field over a period of 2000 years: left column represents the results of regular intrusion of one dike every 40 years; right column represents the results of episodic intrusion of dikes. Several dikes intruded within a relatively short time interval to form a packet of dikes. A. Inclination of magnetic field vs. time; the line represents the inclination of the Earth's field, and dots show the inclinations recorded by dikes at the time of their intrusion. B. Histogram showing relative frequency of dike intrusion. C. Lithologic unit vs. inclination, showing the record expected from a borehole. Note that the regular mode of dike intrusion produces a smooth, continuous variation, whereas the episodic mode of dike intrusion antregular pattern of inclinations.

be expected to be encountered in the approximately $500 \mathrm{~m}$ of sheeted dikes drilled during Leg $137 / 140$, which at a spreading half-rate of $3.6 \mathrm{~cm} /$ year (Hey et al., 1977) would have been accreted in an interval of about 2000 years.

Consider the situation represented in Figure 9 (left column): here we model the dike intrusion as a steady state process, assuming that one 1 -m-thick dike is intruded every 40 years, and that this dike precisely records the paleoinclination of the magnetic field, which varies with a 2000-year period. If a simple model for dike intrusion, based on intrusion with a very narrow central zone (e.g., Kidd and Cann, 1974) is assumed, then the downhole distribution of inclinations should mirror the pattern of secular variation.

In contrast, Figure 9 (right column) shows the predicted distribution of inclinations for an episodic dike-intrusion scheme. In this model the same number of dikes are intruded in the total 2000-year period as in the previous model, but are considered to have been intruded as 
multiples of dikes in relatively short time periods, so that adjacent dikes of the same multiple set have similar inclinations. The pattern of inclinations in this model is similar to that observed in the data.

If the dikes were intruded over a relatively broad zone, an extremely complex dike-intrusion relationship would result, with a randomized distribution of inclinations downhole. The variation in the inclinations observed downhole could result from such an intrusion mechanism.

An important inference is that a large section of the dike sequence must be sampled to give a true estimate of the mean inclination and of the range of inclination values. Equally, large differences of the magnetic inclination of adjacent intervals of core can result from a time-gap in intrusion, rather than from any tectonic process, such as tilting during faulting.

\section{CONCLUSIONS}

The NRM of these samples contains two components, a vertical drilling-induced component, and a shallow, stable component. The DIRM is mostly carried by MD grains with unblocking temperature less than about $400^{\circ} \mathrm{C}$, and coercivities $<25 \mathrm{mT}$. The stable remanence unblocks in temperatures between $350^{\circ} \mathrm{C}$ and $580^{\circ} \mathrm{C}$, and in coercivities between 0 and $100 \mathrm{mT}$.

The DIRM has a greater magnetic hardness than a comparable intensity IRM. We suggest that this DIRM may be a piezoremanence acquired during decompression as the core is brought to the surface. As it is dominantly carried by MD grains, low-temperature/low-field demagnetization may be very effective in removing this component.

The stable remanence is comparable to a laboratory induced TRM acquired in a field of $40 \mu \mathrm{T}$, so this component may either be a TRM or a CRM that mimics a TRM. In addition, the stable inclination and coercivity spectra of altered and unaltered samples do not differ significantly, indicating that hydrothermal alteration reduces the susceptibility and NRM intensity without changing the character of the remanence, so that grains are corroded without being remagnetized.

The inclinations of stable remanence are variable, with a mean of $-18^{\circ} \pm 17^{\circ}$, although the spread on individual lithologic units is frequently smaller (e.g., Unit 227 and Unit 260). Thus each unit records a precise measure of the inclination, which varies from dike to dike. A plausible source of this variation is secular variation, which would produce a similar range. This would require the stable remanence to be a TRM or a rapidly acquired CRM.

Groups of dikes with similar inclinations may have been intruded in relatively quick succession, as dike packets. Thus, the paleomagnetism of the dike sequence may provide a key to the small-scale temporal variations in the spreading process, and provide an important framework for other studies of petrology and alteration.

\section{ACKNOWLEDGMENTS}

We would like to thank Graham Sherwood and Chris MacLeod for careful reviews that significantly improved this manuscript. We also acknowledge discussion with members of the Leg 137 and 140 scientific parties. Special thanks to the officers and crew of the JOIDES Resolution, and to the SEDCO drillers and ODP technicians for making Leg 140 successful and enjoyable. In particular, we thank Daniel Bontempo for keeping the paleomagnetic lab running despite us.

\section{REFERENCES*}

Ade-Hall, J.M., and Johnson, H.P., 1976. Paleomagnetism of basalts, Leg 34 . In Yeats, R.S., Hart, S.R., et al., Init. Repts. DSDP, 34: Washington (U.S. Govt. Printing Office), 513-532.

Alt, J.C., Kinoshita, H., Stokking, L.B., et al., 1993. Proc. ODP, Init. Repts., 148: College Station, TX (Ocean Drilling Program).

Audunsson, H., and Levi, S., 1989. Drilling-induced remanent magnetization in basalt drill cores. Geophys. J., 98:613-622.

Banerjee, S.K., 1980. Magnetism of the oceanic crust: evidence from ophiolite complexes. J. Geophys. Res., 85:3556-3566.
Becker, K., Sakai, H., Adamson, A.C., Alexandrovich, J., Alt, J.C., Anderson, R.N., Bideau, D., Gable, R., Herzig, P.M., Houghton, S.D., Ishizuka, H., Kawahata, H., Kinoshita, H., Langseth, M.G., Lovell, M.A., Malpas, J., Masuda, H., Merrill, R.B., Morin, R.H., Mottl, M.J., Pariso, J.E., Pezard, P.A., Phillips, J.D., Sparks, J.W., and Uhlig, S., 1989. Drilling deep into young oceanic crust, Hole 504B, Costa Rica Rift. Rev. Geophys., 27:79-102.

Coe, R.S., 1967. Paleo-intensities of the Earth's magnetic field determined from Tertiary and Quaternary rocks. J. Geophys. Res., 72:3247-3262.

Davis, P.E., and Evans, M.E., 1976. Interacting single-domain properties of magnetite intergrowths. J. Geophys. Res., 81:989-994.

Dick, H.J.B., Erzinger, J., Stokking, L.B., et al., 1992. Proc. ODP, Init. Repts., 140: College Station, TX (Ocean Drilling Program).

Fox, P.J., and Opdyke, N.D., 1973. Geology of the oceanic crust: magnetic properties of oceanic rocks. J. Geophys. Res., 78:5139-5154.

Hall, J.M., Fisher, B.E., Walls, C.C., Ward, T., Hall, S.L., Johnson, P.H., Bakor, A.R., Agrawal, V., Persaud, M., and Sumaiang, R.M., 1987. Vertical distribution and alteration of dykes in a profile through the Troodos Ophiolite. Nature, 326:780-782.

Hey, R., Johnson, L., and Lowrie, A., 1977. Recent plate motion in the Galapagos Area. Geol. Soc. Am. Bull., 88:1385-1403.

Kelso, P.J., Banerjee, S.K., and Worm, H.-U., 1991. The effect of lowtemperature hydrothermal alteration on the remanent magnetization of synthetic titanomagnetites: a case for acquisition of chemical remanent magnetization. J. Geophys. Res., 96:19545-19553.

Kern, J.W., 1961. Stress stability of remanent magnetization. J. Geophys. Res., 66:3817-3820.

Kidd, R.G.W., and Cann, J.R., 1974. Chilling statistics indicate an ocean floor spreading origin for the Troodos complex, Cyprus. Earth Planet. Sci. Lett., 24:151-155.

Kodama, K.P., 1984. Palaeomagnetism of granitic intrusives from the Precambrian basement under eastern Kansas: orienting drill cores using secondary magnetization components. Geophys. J. R. Astron. Soc., 76:273-287.

Lowrie, W., and Kent, D.V., 1976. Viscous remanent magnetization in basalt samples. In Yeats, R.S., Hart, S.R., et al., Init. Repts. DSDP, 34: Washington (U.S. Govt. Printing Office), 479-484.

McFadden, P.L., and Lowes, F.J., 1981. The discrimination of mean directions drawn from Fisher distributions. Geophys. J. R. Astron. Soc., 67:19-33.

McFadden, P.L., and Merrill, R.T., 1975. Geomagnetic secular variation over the past 5 m.y. Rev. Geophys. Space Phys., 13:687-708.

McFadden, P.L., and Reid, A.B., 1982. Analysis of paleomagnetic inclination data. Geophys. J. R. Astron. Soc., 69:307-319.

McWilliams, M., and Pinto, M.J., 1988. Paleomagnetic results from granitic basement rocks in the Cajon Pass scientific drillhole. Geophys. Res. Lett., 15:1069-1072.

O'Reilly, W., 1984. Rock and Mineral Magnetism: New York (Chapman and Hall).

Pariso, J.E., and Johnson, H.P., 1989. Magnetic properties and oxide petrography of the sheeted dike complex in Hole 504B. In Becker, K., Sakai, H., et al., Proc. ODP, Sci. Results, 111: College Station, TX (Ocean Drilling Program), 159-167.

Pariso, J.E., and Johnson, H.P., 1991. Alteration processes at Deep Sea Drilling Project/Ocean Drilling Program Hole 504B at the Costa Rica Rift: implications for magnetization of oceanic crust. J. Geophys. Res., 96:11703-11722.

Shau, Y.-H., Peacor, D.R., and Essene, E.J., 1993. Formation of magnetic single-domain magnetite in ocean ridge basalts with implications for seafloor magnetism. Science, 261:343-345.

Smith, G.M., and Banerjee, S.K., 1986. The magnetic structure of the upper kilometer of the marine crust at Deep Sea Drilling Project Hole 504B, Eastern Pacific Ocean. J. Geophys. Res., 91:10337-10354.

Thellier, E., and Thellier, O., 1959. Sur l'intensité du champ magnétique terreste dans le passé historique et geologique. Ann. Geophys., 15:285-375.

Verwey, E.J.W., and Haayman, P.W., 1941. Electronic conductivity and transition point in magnetite. Physica, 8:979-982.

Vine, F.J., and Matthews, D.H., 1963. Magnetic anomalies over oceanic ridges. Nature, 199:947-949.

Vine, F.J., and Moores, E.M., 1972. A model for the gross structure, petrology, and magnetic properties of oceanic crust. Mem.-Geol. Soc. Am., 132:195205.

\footnotetext{
Abbreviations for names of organizations and publications in ODP reference lists follow the style given in Chemical Abstracts Service Source Index (published by American Chemical Society).
} 
Date of initial receipt: 11 August 1993

Date of acceptance: 2 February 1994

Ms 137/140SR-030

\section{APPENDIX}

\section{Experimental Procedures}

To avoid burdening the reader with tedious descriptions of laboratory procedures, we have included them in this appendix rather than in the main body of the text.

\section{Temperature Dependence of Low-field Susceptibility}

Temperature dependence of low-field susceptibility of a powdered sample was investigated using a CS-2 furnace in conjunction with a KLY-2 Kappabridge.

\section{Demagnetization}

Static AF demagnetization was undertaken on the drill ship, at $\mathrm{Oxford}$, and in the Department of Geophysics, Texas A\&M University. Thermal demagnetization was done using a Magnetic Measurements oven at Oxford. Measurements of magnetization were made using a $2 \mathrm{G}$ Cryogenic magnetometer on the drill ship, a CCL Cryogenic magnetometer at Oxford, and a CTL cryogenic magnetometer at Texas A\&M. Bulk susceptibility was measured between thermal demagnetization steps.

\section{Modified Thellier-Thellier Experiments}

The Thellier-Thellier method for paleointensity compares the unblocking temperature spectra of the NRM with the blocking temperature spectra of a TRM acquired in a known field. One of the requirements of the technique is that the rock carry a TRM, indicated by a linear correlation between the NRM and the TRM. We can use this requirement to test whether the remanence could be a TRM.

Measurements of magnetization were conducted at Oxford on either a Molspin spinner magnetometer or a CCL cryogenic magnetometer. Thermal demagnetization was completed using a Magnetic Measurements oven having a coil that allows a direct field to be applied during heating for TRM acquisition experiments. The oven was calibrated before the Thellier-Thellier experiments were conducted, and a repeatable accuracy of $<5^{\circ} \mathrm{C}$ was obtained.

In the first experiment the samples were subjected to an incremental treatment procedure, which, following an initial NRM measurement, involved a thermal treatment $\left(T_{n}\right)$ in 0 field and measurement, a thermal treatment $\left(T_{n}\right)$ in $0.04 \mathrm{mT}$ direct field and for alternate steps, a second thermal demagnetization treatment (at $T_{n}$ ). Susceptibility measurements were made after every magnetization measurement.

One of the problems with the method is that the growth and destruction of magnetic minerals significantly influences the blocking temperature spectra of the sample, and this factor needs to be monitored. This has been accomplished in two ways: (1) by repeated thermal demagnetization measurements; (2) by a separate experiment comparing different coercivity fractions at different thermal demagnetization steps.

\section{Low Temperature-Low Field $\left(\mathrm{IN}_{2}\right)$ Treatment}

Low temperature-low field treatment removes the contribution to the remanence of $\mathrm{MD}$ grains from a sample by exploiting the Verwey transition between $-145^{\circ} \mathrm{C}$ and $-155^{\circ} \mathrm{C}$ (Verwey and Haayman, 1941), below which domain walls of multidomain grains are reset. This was accomplished by immersion in liquid nitrogen (boiling point $=-196^{\circ} \mathrm{C}$ at atmospheric pressure) in a $\mu$-metal box, followed by transfer to a second $\mu$-metal box containing water, allowing rapid re-equilibration to room temperature.

\section{Thermal Demagnetization of IRM}

This experiment allowed the unblocking temperature spectra of the MD and PSD/SD magnetic carriers to be determined. It involved a stepwise procedure: (1) IRM magnetization at $0.8 \mathrm{~T}$, (2) heating to progressively higher temperatures in a field-free space, (3) $1 \mathrm{~N}_{2}$ treatment. Measurements between (2) and (3), and after (3) allow the SD + PSD and MD components to be identified.

\section{AF Demagnetization of IRM}

This experiment allowed the coercivity spectra of the MD and PSD/SD magnetic carriers to be determined. In the first part of the experiment an 0.8-T IRM was imparted, and the sample was stepwise demagnetized in an alternating field, up to $100 \mathrm{mT}$. In the second part, this was repeated, with the addition of a $\mathbb{I N}_{2}$ cooling step after the IRM acquisition step, which removed the contribution from the MD grains.

\section{$J_{s}$ After Thermal Treatment}

The changes to the magnetic minerals after heating were monitored by measuring the saturation remanent magnetism after progressive heating steps. After each heating step, an IRM of $0.8 \mathrm{~T}$ was applied, the samples were measured, then cooled in $\mathrm{IN}_{2}$ to remove the $\mathrm{MD}$ component, and then remeasured. 